Jpn. J. Human Genet. 29, 371-380, 1984

\title{
A NOTE ON GENE FREQUENCY ESTIMATION IN THE ABO AND ABO-LIKE SYSTEM
}

\author{
Norikazu YASUDA \\ Division of Genetics, National Institute of Radiological Sciences, \\ Chiba 260, Japan
}

\begin{abstract}
Summary Based on a random sample of individuals, new conventional formulae for estimating gene frequency in the $\mathrm{ABO}$ and the $\mathrm{ABO}-\mathrm{like}$ system are presented. Applying the formulae on a large number of samples, it is found that the new method is simple and yields estimates as accurate in at least two decimal places as the maximum likelihood solutions. The method however might be fraught with bias when the $O$ phenotype frequency was low or even absent. Degrees of this bias have been discussed in terms of the number of iterative processes by a method of gene counting and of a goodness of fit to the Hardy-Weinberg proportions.
\end{abstract}

\section{INTRODUCTION}

Several authors have already developed formulae for estimating gene frequency in the ABO blood groups (Bernstein, 1925; Wiener et al., 1929; Stevens, 1938; Fisher, 1946; Yasuda and Kimura, 1968). Although recent advents of electronic computer have made it feasible to calculate the $\mathrm{ABO}$ gene frequency as the maximum likelihood solution, a simple and biologically sound formula may be still of use. This note based on a method of gene counting (Ceppellini et al., 1955) is an addition of conventionally useful formulae in the sense that the derived estimate is in good agreement with the maximum likelihood solution and that the calculations are manageable by a desk calculator without iteration. In the followings, a random sampling of individuals is assumed.

\section{FORMULAE}

The $A B O$ system. Let $\mathrm{p}, \mathrm{q}$ and $\mathrm{r}$ be allelic frequency of $\mathrm{A}, \mathrm{B}$ and $\mathrm{O}$, respectively. The observed numbers of four phenotypes in population are designated by the phenotype symbols themselves as $\mathrm{O}, \mathrm{A}, \mathrm{B}$ and $\mathrm{AB}$ so that the observed number 
of sample is $\mathrm{T}=\mathrm{O}+\mathrm{A}+\mathrm{B}+\mathrm{AB}$. The new formulae for estimating the $\mathrm{ABO}$ gene frequency are

$$
\begin{aligned}
& \hat{\mathrm{p}}=[1 / 2 \mathrm{AB}+\mathrm{A}+\mathrm{O}-\sqrt{\mathrm{O}(\mathrm{A}+\mathrm{O})}] / \mathrm{T}, \\
& \hat{\mathrm{q}}=[1 / 2 \mathrm{AB}+\mathrm{B}+\mathrm{O}-\sqrt{\mathrm{O}(\mathrm{B}+\mathrm{O})}] / \mathrm{T} \\
& \hat{\mathrm{r}}=1-\hat{\mathrm{p}}-\hat{\mathrm{q}} \text {. }
\end{aligned} \text { and }
$$

A derivation of the formulae is given in appendix.

The ABO-like system. An extension of the ABO system to include an arbitrary number of codominant alleles has been made, and such a multiple allele locus has been called the ABO-like system (Yasuda and Kimura, 1968). Obviously, one of the most important examples in this genetic system is the HLA polymorphisms.

Suppose that $m-1$ codominant alleles, $A_{1}, A_{2}, \ldots, A_{m-1}$ and a null allele $O$ have the frequency $\mathrm{p}_{1}, \mathrm{p}_{2}, \ldots, \mathrm{p}_{\mathrm{m}-1}$ and $\mathrm{r}$, respectively. Let the symbol of phenotypes designate for the observed number. The following formulae are obtained:

$$
\left.\begin{array}{l}
\hat{p}_{1}=\left[1 / 2 H_{1}+A_{i}+O-\sqrt{O\left(A_{i}+O\right)}\right] / T \quad \text { for } i=1,2, \ldots, m-1 \\
\hat{r}=1-\hat{p}_{1}-\hat{p}_{2}-\ldots-\hat{p}_{m-1}
\end{array}\right\}
$$

where $H_{1}$ is the sum of observed numbers of heterozygotes who carry $A_{i}$ and the one of the other detectable antigens or mathematically, $\mathrm{H}_{\mathrm{i}}=\sum_{\mathrm{j} \neq \mathrm{i}} \mathrm{A}_{\mathrm{i}} \mathrm{A}_{\mathrm{j}}$.

The $A_{1} A_{2} B O$ system. Suppose that $\mathrm{p}_{1}, \mathrm{p}_{2}, \mathrm{q}$ and $\mathrm{r}$ were allelic frequency of $\mathrm{A}_{1}, \mathrm{~A}_{2}, \mathrm{~B}$ and $\mathrm{O}$, respectively. The new formulae will be

$$
\begin{aligned}
& \hat{\mathrm{p}}_{1}=\left[1 / 2 \mathrm{~A}_{1} \mathrm{~B}+\mathrm{A}_{1}+\mathrm{A}_{2}+\mathrm{O}-\sqrt{\left(\mathrm{A}_{2}+O\right)\left(\mathrm{A}_{1}+\mathrm{A}_{2}+O\right)}\right] / T \\
& \hat{\mathrm{p}}_{2}=\left[1-\sqrt{\mathrm{O} /\left(\mathrm{A}_{2}+O\right)}\right]\left(1-\hat{\mathrm{p}}_{1}-\hat{\mathrm{q}}\right) \\
& \hat{\mathrm{q}}=\left[1 / 2\left(\mathrm{~A}_{1} \mathrm{~B}+\mathrm{A}_{2} \mathrm{~B}\right)+\mathrm{B}+\mathrm{O}-\sqrt{\mathrm{O}(\mathrm{B}+\mathrm{O})}\right] / \mathrm{T} \quad \text { and } \\
& \hat{\mathrm{s}}=\left[\sqrt{\mathrm{O} /\left(\mathrm{A}_{2}+O\right)}\right]\left(1-\hat{\mathrm{p}}_{1}-\hat{\mathrm{q}}\right) .
\end{aligned}
$$

For a derivation, see appendix.

\section{APPLICATIONS}

The ABO system. Fujita et al. (1978) have reported extensive data on the ABO blood groups of all Japan. The total number of individuals, $T=4,464,349$, was classified into $\mathrm{O}=1,305,924, \mathrm{~A}=1,725,950, \mathrm{~B}=988,996$ and $\mathrm{AB}=444,479$. The conventional formulae (1) yielded $\hat{p}=0.28313, \hat{q}=0.17602$ and $\hat{x}=0.54085$, those of which could be comparable with the maximum likelihood solutions; $p=0.28312$, $\mathrm{q}=0.17601$ and $\mathrm{r}=0.544087$. In this particular example, the conventional estimates agree in four decimal places to the maximum likelihood solutions. The value of chisquare for a goodness of fit to the Hardy-Weinberg proportions is 1.1761 with one degree of freedom which is not significant.

Now, the following question would be of interest; how many number of iterative processes should it be necessary for arriving at the maximum likelihood so- 
lution with allowing a given amount of error when one started at the trial value calculated by the new formulae and then applied a method of gene counting to it? In order to find a practical answer to this question, four hundreds and ninetytwo independent subpopulations reported by Fujita et al. (1978) have subjected to analysis with an error criterion

$$
E=|\hat{p}-p|+|\hat{q}-q|+|\hat{r}-r|<10^{-6} \text {. }
$$

This infers that both estimates should agree in four decimal places. Results are shown in Table 1 in which the number of iterative processes is distributed in terms of the chisquare for a goodness of fit to the Hardy-Weinberg proportions (the corresponding probability is also given). Mean number of iterative processes and the standard deviation were 4.30 and 0.86 , respectively. The mean number reduced to one and/or two when two decimal places were concerned in the estimates. This suggests that the new formulae (1) are very practical. Table 1 also indicates that there seems no association the number of iterative processes with the value of chisquare for a goodness of fit to the Hardy-Weinberg proportions. Incidentally, of eighteen percent (89/492) populations gathered from prefectural health departments, health centers, and Red Cross blood centers in the whole country, a goodness of fit to the Hardy-Weinberg proportions was significantly deviated at least five percent or higher level.

The ABO-like system. As an extension of the $\mathrm{ABO}$ system, HLA-DR antigen

Table 1. Distribution of the iterative number a and the chisquare value for a goodness of fit to the Hardy-Weinberg proportions in the ABO blood groups of 492 independent populations in Japan (After Fujita et al., 1978).

\begin{tabular}{ccccccccccc}
\hline \multirow{2}{*}{$\begin{array}{c}\text { Value of } \\
\text { chisquare }\end{array}$} & $\begin{array}{c}\text { Probability } \\
(\%)\end{array}$ & 1 & 2 & 3 & 4 & 5 & 6 & 7 & Total \\
\hline 0 & -0.45 & $100-50$ & 2 & 13 & 51 & 103 & 15 & - & - & 184 \\
$0.45-1.07$ & $50-30$ & - & - & - & 51 & 20 & 4 & - & 75 \\
$1.07-1.64$ & $30-20$ & - & - & - & 26 & 26 & 3 & - & 55 \\
$1.64-2.71$ & $21-10$ & - & - & - & 21 & 34 & 4 & - & 59 \\
$2.71-3.84$ & $10-5$ & - & - & - & 8 & 19 & 2 & 1 & 30 \\
$3.84-5.02$ & $5-2.5$ & - & - & - & 4 & 18 & 4 & - & 26 \\
$5.02-6.63$ & $2.5-1.0$ & - & - & - & 3 & 11 & 2 & - & 16 \\
$6.63-7.88$ & $1.0-0.5$ & - & - & - & - & 8 & 1 & - & 9 \\
$7.88-10.83$ & $0.5-0.1$ & - & - & - & 2 & 8 & 3 & - & 13 \\
$10.83-\infty$ & $0.1-0$ & - & - & - & 4 & 18 & 3 & - & 25 \\
\hline Total & & 2 & 13 & 51 & 222 & 177 & 26 & 1 & 492 \\
\hline
\end{tabular}

a Error in estimate is less than $10^{-6}$. Mean and the standard deviation of iterative numbers are 4.30 and 0.86 , respectively.

Vol. 29; No. 3, 1984 


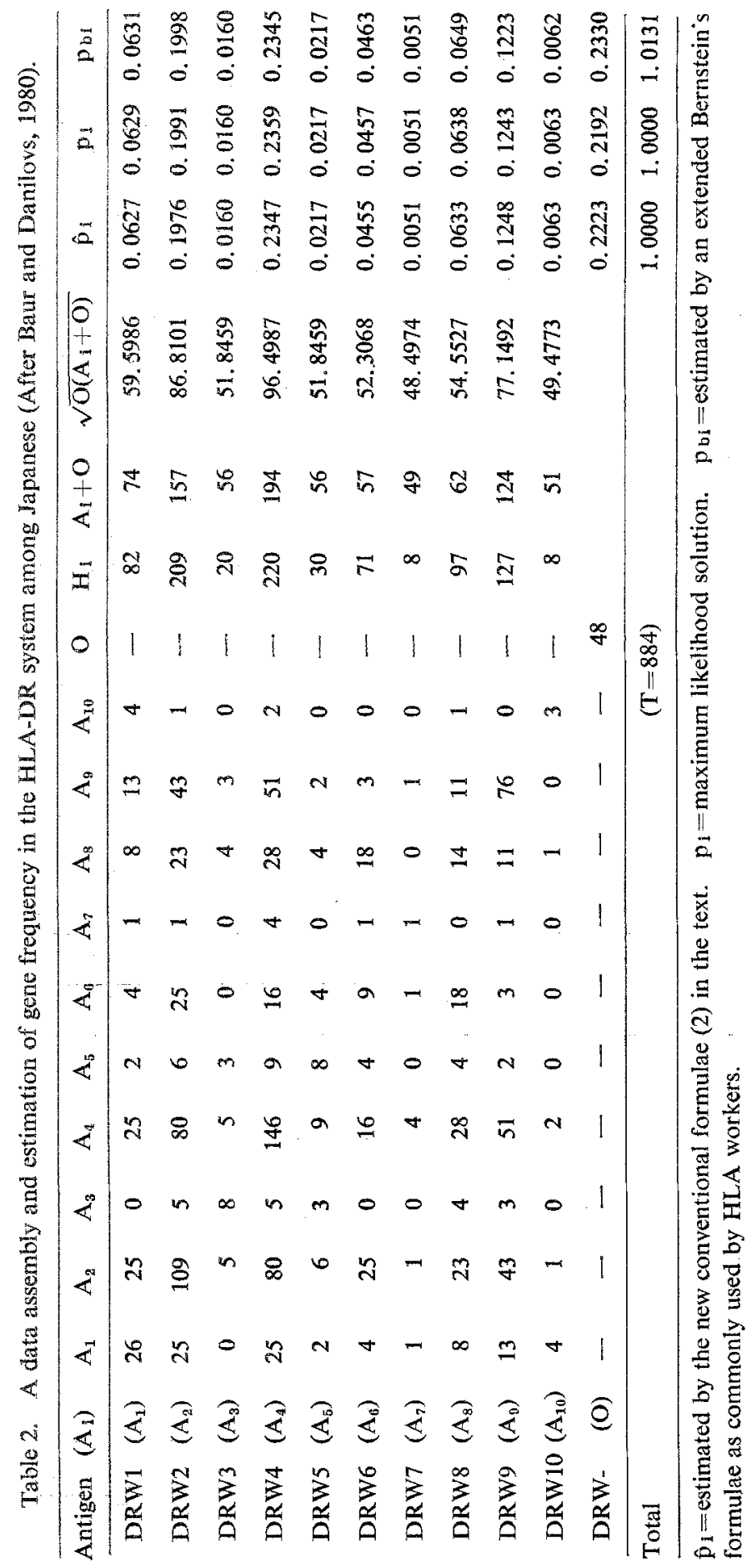


phenotypes in the HLA system on Japanese population (Baur and Danilovs, 1980) have been taken for an illustration. Table 2 shows a way of assembling data for the computation of the HLA-DR gene frequency. The row and column indicate the HLA-DR antigens and each entry of the table represents the observed number of phenotype. The diagonal entries are the observed number of individuals who carry a corresponding single antigen detected, while that of heterozygotes is given in the off-diagonal entries in duplicate. For instance, the number of individuals who carry HLA-DRW1 $\left(A_{1}\right)$ and HLA-DRW1/DRW2 $\left(A_{1} / A_{2}\right)$ are respectively 26 and 25 , the number of heterozygotes having HLA-DRW1 $\left(A_{1}\right)$ is $H_{1}=0+25+2+$ $4+1+8+13+4=82$, and $A_{1}+O=26+48=74$. Agreement of the estimates with the maximum likelihood solutions is satisfactory at least in two decimal places. Another conventional estimates by the extended Bernstein's formulae, commonly used by HLA-worker, are also given in Table 2 for the sake of comparison. Both conventional methods lead to very similar solutions in this particular example.

$A_{1} A_{2} B O$ blood groups. Four hundreds and eighty worldwide samples compiled by Mourant et al. (1976) were subjected to the new formulae (3). Having an error criterion

$$
\mathrm{E}=\left|\hat{\mathrm{p}}_{1}-\mathrm{p}_{1}\right|+\left|\hat{\mathrm{p}}_{2}-\mathrm{p}_{2}\right|+|\hat{\mathrm{q}}-\mathrm{q}|+|\hat{\mathrm{r}}-\mathrm{r}|<4 \times 10^{-5}
$$

which assured four decimal places in accuracy, two populations showed extreme numbers of iterative processes (Table 3). One sample was Amish from Lancaster country of Pennsylvania (McKusick et al., 1967) and comprised $\mathrm{O}=23, \mathrm{~A}_{1}=140$,

Table 3. Distribution of the iterative number a and the value of chisquare for a goodness of fit to the Hardy-Weinberg proportions in the $\mathrm{A}_{1} \mathrm{~A}_{2} \mathrm{BO}$ blood groups of 480 populations in the worldwide (After Table 1.2 of Mourant et al., 1976).

\begin{tabular}{|c|c|c|c|c|c|c|c|c|c|c|c|c|c|c|c|c|}
\hline \multirow{2}{*}{$\begin{array}{l}\text { Value of } \\
\text { chisquare }\end{array}$} & \multirow{2}{*}{$\begin{array}{c}\text { Probability } \\
(\%)\end{array}$} & \multicolumn{15}{|c|}{ Iterative number } \\
\hline & & 1 & 2 & 3 & 4 & 5 & 6 & 7 & 8 & 9 & 10 & 11 & 12 & 13 & 14 & Total \\
\hline $\begin{array}{ll}0 & -1.38\end{array}$ & $100-50$ & 7 & 12 & 38 & 93 & 58 & 12 & 1 & 1 & - & - & - & - & - & - & 222 \\
\hline $1.38-2.40$ & $50-30$ & - & - & 9 & 32 & 24 & 8 & 1 & - & - & - & - & - & - & - & 74 \\
\hline $2.40-3.21$ & $30-20$ & - & - & 3 & 12 & 22 & 6 & - & - & - & - & - & - & - & - & 43 \\
\hline $3.21-4.60$ & $20-10$ & - & 1 & 3 & 18 & 17 & 9 & 2 & - & - & - & - & 1 & - & - & 51 \\
\hline $4.60-5.99$ & $10-5$ & - & - & - & 13 & 15 & 2 & 1 & 2 & - & - & - & - & - & - & 33 \\
\hline $5.99-7.37$ & $5-2.5$ & - & - & 1 & 1 & 7 & 2 & 1 & 1 & - & - & 一 & - & - & - & 13 \\
\hline $7.37-9.21$ & $2.5-1.0$ & - & - & 1 & 2 & 4 & 3 & - & - & - & - & - & - & - & - & 10 \\
\hline $9.21-10.59$ & $1.0-0.5$ & - & - & 1 & 1 & 6 & 1 & - & - & - & - & - & - & - & - & 9 \\
\hline $10.59-13.81$ & $0.5-0.1$ & - & - & - & 4 & 4 & 1 & - & - & - & - & - & - & - & 1 & 10 \\
\hline $13.81-\infty$ & $0.1-0$ & - & 1 & 3 & 4 & 4 & 3 & - & - & - & - & - & - & - & - & 15 \\
\hline Total & & 7 & 14 & 59 & 180 & 161 & 47 & 6 & 4 & - & - & - & 1 & - & 1 & 480 \\
\hline
\end{tabular}

a Error in estimate is less than $4 \times 10^{-5}$. Mean and the standard deviation of iterative numbers are 4.4 and 3.9 , respectively. 
$A_{2}=19, B=10, A_{1} B=15$ and $A_{2} B=8$ so that $T=215$. The formulae (3) yielded $\hat{\mathrm{p}}_{1}=0.47474, \hat{\mathrm{p}}_{2}=0.11606, \hat{\mathrm{q}}=0.07884$ and $\hat{\mathrm{r}}=0.33036$ so that $\chi^{2}=4.81$ with two degrees of freedom. By applying a method of gene counting (Yasuda and Kimura, 1968), in which a formula for $A_{2}$ was in error and should read as $p_{2}=\left[A_{2}+A_{2} B+\right.$ $\left.A_{2} h_{A_{2}}+A_{1} h_{A_{1} 2}\right] / 2 T\left(h_{A_{12}}\right.$ is the probability that $A_{1}$ individual carries $A_{2}$ allele), twelve iterations were required for arriving at the maximum likelihood estimates; $\mathrm{p}_{1}=$ $0.47302, p_{2}=0.13473, q=0.07936$ and $r=0.31288$ with $\chi^{2}=3.54$. The other sample from India (Jalpainquri Toto) (Chaudhuri et al., 1962) resulted 14 cycles of iteration. Here, we have $O=3, A_{1}=27, A_{2}=6, B=61, A_{1} B=11$ and $A_{2} B=7$ so that $T=115$. The conventional estimates by (3) were $\hat{p}_{1}=0.20435, \hat{p}_{2}=0.11892, \hat{q}=0.51429$ and $\hat{\mathrm{r}}=0.16244$ with $\chi^{2}=17.80$ while the maximum likelihood solutions were $\mathrm{p}_{1}=0.19106$, $\mathrm{p}_{2}=0.08244, \mathrm{q}=0.47049$ and $\mathrm{r}=0.25601$ with $\chi^{2}=12.15$ which was highly significant. A large number of itereative processes here would be due to a low number of $O$ phenotype, the point to be discussed later.

Mean and standard deviation of the number of iterative processes in this set of -worldwide samples are 4.4 and 3.9, respectively. Again, no association was found between the number of iterative processes and the value for a goodness of fit to the Hardy-Weinberg proportions.

\section{DISCUSSION}

For all practical purposes, any conventional formula for estimating gene frequency should be manageable with a desk calculator and yields a biologically as well as statistically sound solution. The formulae presented in this paper must meet these conditions. However, during applications of the new formulae on random samples of $\mathrm{ABO}$ or $\mathrm{ABO}-\mathrm{like}$ system, it was revealed that the frequency of $O$ (or null) phenotype affected critically the accuracy of the estimates. That is, lower the frequency of $O$ phenotype is, the large number of iterations is required. $B y$ any means, the $O$ gene frequency could not be estimated from population data of the $A B O$ system when no $O$ individual was observed. Retabulating Table 1 according to the number of $\mathrm{O}$ phenotype in each population, a trend of negative association between the number of iterations and the observed number of $O$ phenotype was noted (Table 4). The trend was enhanced in the Duffy blood groups where two codominant alleles, $\mathrm{Fy}^{\mathrm{a}}$ and $\mathrm{Fy}^{\mathrm{b}}$, and a silent allele, Fy, corresponded to the allele $\mathrm{A}, \mathrm{B}$ and $\mathrm{O}$ in the $\mathrm{ABO}$ blood groups, and the frequency of Fy $(\mathrm{a}-\mathrm{b}-)$ phenotype is usually absent but is common in some groups (Race and Sanger, 1975). In Table 5 a result of analysis on twenty samples presented in Table 8.3.2 of Mourant et al. (1976) was tabulated in an ascending order of Fy(a-b-) proportion. The negative association is now very clear. The population, which was the lowest frequency of the silent phenotype in Table 5 (Bjarnason et al., 1968), consisted of $F y(a-b-)=1, F y(a+b-)=436$, Fy $(a-b+)=548$ and $F y(a+b+)=$ 703 so that $\mathrm{T}=1,688$, and yielded by the formulae (l) $\mathrm{Fy}^{\mathrm{a}}=0.45474, \mathrm{Fy}^{\mathrm{b}}=0.51959$ 
Table 4. Distribution of the iterative number, a the number of $O$ phenotype in the sample, and the value of chisquare for a goodness of fit to the Hardy-Weinberg proportions in the ABO blood groups of 492 independent populations in Japan (After Fujita et al., 1978).

\begin{tabular}{|c|c|c|c|c|c|c|c|c|}
\hline \multirow{2}{*}{$\begin{array}{l}\text { No. of O } \\
\text { phenotype }\end{array}$} & \multicolumn{8}{|c|}{ Iterative number } \\
\hline & 1 & 2 & 3 & 4 & 5 & 6 & 7 & Total \\
\hline $1-\quad 10$ & - & - & - & 1 & - & 1 & 1 & 3 \\
\hline $11-\quad 20$ & - & - & - & 2 & 1 & 4 & - & 7 \\
\hline $21-\quad 50$ & - & - & - & - & $2(2)^{*}$ & 3 & - & $5(2)$ \\
\hline $51-\quad 100$ & - & 1 & - & 7 & 5 & $4(2)$ & - & $17(2)$ \\
\hline $101-200$ & - & - & 3 & 12 & $13(1)$ & $1(2)$ & - & $29(3)$ \\
\hline $201-500$ & - & 1 & 6 & $32(1)$ & $44(10)$ & $-(5)$ & - & $83(16)$ \\
\hline $501-1,000$ & - & 1 & 5 & 36 & $28(17)$ & $-(3)$ & - & $70(20)$ \\
\hline $1,001-2,000$ & 1 & 6 & 10 & 52 & $14(17)$ & $-(1)$ & - & $83(18)$ \\
\hline $2,001-5,000$ & - & 3 & 13 & $47(4)$ & $7(12)$ & - & - & $70(16)$ \\
\hline $5,001-10^{4}$ & 1 & - & 8 & $14(5)$ & $-(4)$ & - & - & $23(9)$ \\
\hline $10^{4}-\infty$ & - & 1 & 6 & $6(3)$ & - & - & - & $13(3)$ \\
\hline Total & 2 & 13 & 51 & $209(13)$ & $114(63)$ & $13(13)$ & 1 & $403(89)$ \\
\hline
\end{tabular}

a Error in estimate is less than $10^{-6}$. * Number in parentheses is the number of populations which have shown a statistical significance at $5 \%$ or higher level for a goodness of fit to the Hardy-Weinberg proportions.

Table 5. The number of iterative processes, frequency of silent phenotype, and the value of chisquare for a goodness of fit to the Hardy-Weinberg proportions in the Duffy blood groups (After Table 8.3.2 of Mourant et al., 1976).

\begin{tabular}{cccccccccc}
\hline Sample & Fy $(\mathrm{a}-\mathrm{b}-) / \mathrm{T}$ & $(\%)$ & no. & $\chi^{2}(\mathrm{df}=1)$ & Sample & Fy $(\mathrm{a}-\mathrm{b}-) / \mathrm{T}$ & $(\%)$ & no.a & $\chi^{2}(\mathrm{df}=1)$ \\
\hline 1 & $1 / 1,688$ & 0.06 & 46 & $8.71^{*}$ & 11 & $169 / 496$ & 34.07 & 4 & 0.08 \\
2 & $1 / 128$ & 0.78 & 26 & 0.65 & 12 & $34 / 95$ & 35.79 & 4 & 0.05 \\
3 & $4 / 107$ & 3.74 & 14 & $5.22^{*}$ & 13 & $142 / 236$ & 60.17 & 3 & 1.57 \\
4 & $4 / 99$ & 4.07 & 12 & 0.16 & 14 & $108 / 179$ & 60.33 & 4 & $5.69^{*}$ \\
5 & $4 / 94$ & 4.25 & 13 & $3.97^{*}$ & 15 & $59 / 97$ & 60.82 & 3 & 0.75 \\
6 & $4 / 77$ & 5.19 & 12 & $4.26^{*}$ & 16 & $46 / 75$ & 61.33 & 4 & $4.01^{*}$ \\
7 & $2 / 27$ & 7.40 & 10 & 1.11 & 17 & $85 / 125$ & 68.00 & 3 & 0.09 \\
8 & $11 / 88$ & 12.50 & 8 & 3.04 & 18 & $226 / 236$ & 95.76 & 2 & $163.67^{*}$ \\
9 & $30 / 200$ & 15.00 & 7 & 1.04 & 19 & $249 / 260$ & 95.76 & 2 & $99.96^{*}$ \\
10 & $58 / 174$ & 33.33 & 5 & 2.52 & $20 *$ & $1,149 / 1,162$ & 98.88 & 1 & 0.02 \\
\hline
\end{tabular}

$\mathrm{T}=$ sample size. $\%=$ proportion of $\mathrm{Fy}(\mathrm{a}-\mathrm{b}-)$ phenotype in the sample. no. =number of iterative processes. $\chi^{2}=$ value of chisquare for a goodness of fit to the Hardy-Weinberg proportions. a Error in estimate is less than $10^{-6}$. The phenotype Fy $(a+b+)$ was absent. * Significant at $5 \%$ or higher level.

Vol. 29, No. 3, 1984 
Table 6. A comparison of gene frequencies estimated by three methods in the HLA-A system from an Okinawa study (After Yasuda and Tusji, 1975)

\begin{tabular}{rccc}
\hline $\mathrm{A}$ & $\hat{\mathrm{p}}_{1}$ & $\mathrm{p}_{1}$ & $\mathrm{p}_{\mathrm{bi}}$ \\
\hline 1 & 0.0346 & 0.0190 & 0.0174 \\
2 & 0.5172 & 0.4211 & 0.4128 \\
9 & 0.3103 & 0.2643 & 0.2300 \\
10 & 0.1379 & 0.0924 & 0.1094 \\
- & 0.0000 & 0.2032 & 0.0000 \\
\hline Total & 1.0000 & 1.0000 & 0.7696 \\
\hline
\end{tabular}

$A=$ HLA-A antigen. $\hat{p}_{i}=$ estimated by the new formulae (2) in the text. $p_{i}=$ maximum likelihood estimate. $p_{b i}=$ estimated by an extended Bernstein's formula.

and $\mathrm{Fy}=0.02567$ with $\chi^{2}=21.52$ while after 46 times of iteration the maximum likelihood solution accurate to four decimal places was $\mathrm{Fy}^{\mathrm{a}}=0.43959, \mathrm{Fy}^{\mathrm{b}}=0.50246$ and $F y=0.05796$ with $\chi^{2}=8.72$. In this particular example, the Fy gene estimated by (1) was only of 44.5 percent that of the solution of maximum likelihood.

In the ABO-like system, the above problem would become rather serious, especially when no null phenotype is observed, but the estimation indicates the existance of null alleles in heterozygous conditions with more than two codominant alleles. Such a typical example in the HLA polymorphisms (Yasuda and Tsuji, 1975) yielded the result shown in Table 6 . The estimated gene frequencies for four codominant alleles by the formulae (2) were far different from the maximum likelihood solutions. Rather, in this special example, the commonly used Bernstein's formula gave good estimates for these alleles, except the null allele. It is a matter of conjecture that whether implementation of heterozygous phenotypes in the new formulae, comparable with the Bernstein's formulae in which homozygous phenotypes were only taken into account, made this difference.

The situation seems to be the same even in $A_{1} A_{2} B O$ blood groups as already mentioned. The new conventional formulae will give an underestimate for the $O$ (or null) gene frequency when the number of $O$ individuals was small in the sample. Nevertheless, the new formulae provide first order approximations and trial values for further improvement such as the maximum likelihood solutions by a gene counting which has never failed to converge, at least in the $\mathrm{ABO}$ and the $\mathrm{ABO}-\mathrm{like}$ system examined so far.

Acknowledgments The author would like to thank Mr. Kanjiro Fukuhisa for his technical assistance in running computer programs on ACOS-700S installed in the National Institute of Radiological Sciences. For the excellent secretarial assistance the author is grateful to Mrs. Hiroko Itoh.

This study was supported in part by a grant for the Intractable Diseases from Ministry of Health and Welfare, Japan. 


\section{REFERENCES}

Baur, M.P. and Danilovs, J.A. 1980. Population analysis of HLA-A, B, C, DR and other genetic markers. In Histocompatibility Testing 1980, Terasaki, P., ed., UCLA Tissue Typing Laboratory, Los Angeles, pp. 955-993.

Bernstein, F. 1925. Zusammenfassende Betrachtungen über die erblichen Blutstrukturen des Menschen. Z. Indukt. Abstamm. -u. Vereblehre 37: 237-270.

Bjarnason, O., Bjarnason, U., Edwards, J.H., Fridriksson, S., Godber, M.J., Mourant, A.E., Tills, D., and Woodhead, B.G. 1968. Unpublished observaticn (Cited in Mourant, A.E., Kopec, A.C., and Domaniewska-Sobczak, K., 1976).

Ceppellini, R., Siniscalco, M., and Smith, C.A.B. 1955. The estimation of gene frequencies in a random mating population. Ann. Human Genet. 20: 97-115.

Chaudhuri, S., Chakuravartti, M.R., Mukherjee, B., Sen, S.N., Ghosh, J., and Maitra, A. 1964. A study of haematological factors, blood groups, anthropometric measurements and genetics of some of the tribal and caste groups of: South India-Kerala, Nilgiris and Andhra Predesh. 2. North eastern India (Indo-Bhutan border). Totopara. 9th Congr. Int. Soc. Blood Transfus., Mexico 1962. Bibl. Haemat. 19: 196-205, 1964 (Cited in Mourant, A.E., Kopec, A.C., and Domaniewska-Sobczak, K., 1976).

Fisher, R.A. 1946. In Dobson, A.M. and Ikin, E.W. 1946. The ABO blood groups in the United Kingdom; frequencies based on a very large population. J. Pathol. Bact. 48: 221-227.

Fujita, Y., Tanimura, M., and Tanaka, K. 1978. The distribution of the ABO blood groups in Japan. Jpn. J. Human Genet, 23: 63-109.

McKusick, V.A., Bias, W.B., Norum, R.A., and Cross, H.E. 1967. Blood groups in two Amish demes. Humangenetik 5: 36-41 (Cited in Mourant, A.E., Kopec, A.C., and DomaniewskaSobczak, K., 1976).

Mourant, A.E., Kopec, A.C., and Domaniewska-Sobczak, K.1976. The Distribution of the Human Blood Groups and Other Polymorphisms (2nd ed.), Oxford Univ. Press, London.

Race, R.R. and Sanger, R. 1975. Chapter 10. The Duffy blood groups. In Blood Groups in Man (6th ed.), Blackwell Scientific Publications, Oxford, pp. 350-363.

Stevens, W.L. 1938. Estimation of blood-group gene frequencies. Ann. Eugen. 8: 362-375.

Wiener, A.S., Lederer, M., and Polayes, S.H. 1929. Studies in isoheamagglutination. I. Theoretical considerations, J. Immun. (Balt.) 16: 469-482.

Yasuda, N. 1980. A note on gene frequency estimation in the ABO blood group system. Ann. Rep. Natl. Inst. Radiol. Sci. NIRS-20: 47-48.

Yasuda, N. and Kimura, M. 1968. A gene-counting method of maximum likelihood for estimating gene frequencies in ABO and ABO-like systems. Ann. Human Genet., Lond. 31: 409-420.

Yasuda, N. and Tsuji, K. 1975. A counting method of maximum likelihood for estimating haplotype frequency in the HLA system. Jpn. J. Human Genet. 20: 1-15.

\section{APPENDIX}

A derivation of the new conventional formulae

The $A B O$ system. Using the notation in the text, the method of gene counting yields the followings:

$$
\text { and } \left.\quad \begin{array}{l}
\mathrm{p}=\left[\mathrm{AB}+\mathrm{A}+\mathrm{Ah}_{\mathrm{A}}\right] / 2 \mathrm{~T}, \\
\mathrm{q}=\left[\mathrm{AB}+\mathrm{B}+\mathrm{Bh}_{\mathrm{B}}\right] / 2 \mathrm{~T}
\end{array}\right\}
$$


In which $h_{\mathrm{A}}=p /(p+2 r)$ and $h_{B}=q /(q+2 r)$ (Yasuda and Kimura, 1968). Now, let us consider observable quantities

$$
k_{A}=O /(A+O) \text { and } k_{B}=O /(B+O) \text {. }
$$

In terms of the expectation k's could be expressed as

$$
\begin{aligned}
k_{\mathrm{A}} & =\operatorname{Tr}^{2} /\left[\mathrm{T}\left(\mathrm{p}^{2}+2 \mathrm{pr}\right)+\operatorname{Tr}^{2}\right]=[\mathrm{r} /(\mathrm{p}+\mathrm{r})]^{2} \\
\text { and } \mathrm{k}_{\mathrm{B}} & =[\mathrm{r} /(\mathrm{q}+\mathrm{r})]^{2} \text {. }
\end{aligned}
$$

Then h's in (AI) can be expressed as

$$
\begin{aligned}
h_{A} & =\left(1-\sqrt{k_{A}}\right)^{2} /\left(1-k_{A}\right) \\
\text { and } h_{B} & =\left(1-\sqrt{k_{B}}\right)^{2} /\left(1-k_{B}\right) .
\end{aligned}
$$

Or, in terms of the observed number of phenotype, we have

$$
\text { and } \quad \begin{aligned}
& \mathrm{Ah}_{\mathrm{A}}=\mathrm{A}+2 \mathrm{O}-2 \sqrt{\mathrm{O}(\mathrm{A}+\mathrm{O})} \\
& \mathrm{Bh}
\end{aligned}
$$

Substituting (A2) for (A1), the new formulae (1) in the text can be derived (Yasuda, 1980). The derivation of the formulae (2) in the ABO-like system is essentially the same.

$A_{1} A_{2} B O$ blood groups. For allele $\mathrm{A}_{1}$ and $\mathrm{B}$, the derivation is the same as that of the ABO system. Then the following simultaneous equations hold and can be solved in terms of $\mathrm{p}_{2}$ and $\mathrm{r}$;

$$
\left\{\begin{array}{l}
\mathrm{p}_{2}+\mathrm{r}=1-\hat{\mathrm{p}}_{1}-\hat{\mathrm{q}} \\
{\left[\mathrm{r} /\left(\mathrm{p}_{2}+\mathrm{r}\right)\right]^{2}=\mathrm{O} /\left(\mathrm{A}_{2}+\mathrm{O}\right)}
\end{array}\right.
$$

Namely,

$$
\begin{aligned}
\hat{\mathrm{r}} & =\sqrt{\mathrm{O} /\left(\mathrm{A}_{2}+\mathrm{O}\right)}\left(1-\hat{\mathrm{p}}_{1}-\hat{\mathrm{q}}\right) \\
\text { and } \hat{\mathrm{p}}_{2} & =\left[1-\sqrt{\mathrm{O} /\left(\mathrm{A}_{2}+O\right)}\right]\left(1-\hat{\mathrm{p}}_{1}-\hat{\mathrm{q}}\right) .
\end{aligned}
$$

In principle, the above procedure can be applied to any genetic system and would provide a simple and practical formula for gene frequency estimation. 